\title{
New Theoretical Modelling of Heat Transfer in Solar Ponds
}

\author{
Assad H. Sayer*1,2 \\ a.h.sayer@surrey.ac.uk \\ * Corresponding author. Tel +44 1483686562 \\ Hazim Al-Hussaini ${ }^{1}$ \\ h.al-hussaini@surrey.ac.uk \\ Alasdair N. Campbell ${ }^{1}$ \\ a.n.campbell@surrey.ac.uk \\ ${ }^{1}$ Department of Chemical and Process Engineering, Faculty of Engineering and Physical \\ Sciences, University of Surrey GU2 7XH, UK \\ ${ }^{2}$ University of Thi-Qar, College of Science, Chemistry Department, Thi-Qar-Iraq
}

\begin{abstract}
Solar energy has a promising future as one of the most important types of renewable energy. Solar ponds can be an effective way of capturing and storing this energy. A new theoretical model for a heat transfer in a salinity gradient solar pond has been developed. The model is based on the energy balance for each zone of the pond; three separate zones have been considered, namely the upper convective zone, the lower convective zones, as well as the non-convective zone. The upper and lower zones are considered to be well mixed, which means the temperatures in these zones are uniform. The model shows that the temperature in the storage zone can reach more than $90{ }^{\circ} \mathrm{C}$ during the summer season whereas it can be more than $50{ }^{\circ} \mathrm{C}$ in winter if the pond is located in the Middle East. In addition, the time dependent temperature for the three layers has been found. Furthermore, it is concluded that heat loss from the pond's surface occurs mainly by evaporation, in comparison to convection and radiation. Heat loss to the ground has been calculated by using three different equations. It was found that the perimeter of the pond has a significant effect on heat loss to the ground from a small pond, while its effect is small in the case of large pond. The validity of the model is tested against experimental data for several established ponds; good agreement is observed.
\end{abstract}


$A_{b} \quad$ Area of the bottom surface of the pond $\left(\mathrm{m}^{2}\right)$

$A_{l} \quad$ Surface area of the $\operatorname{LCZ}\left(\mathrm{m}^{2}\right)$

$A_{u} \quad$ Surface area of the $\operatorname{UCZ}\left(\mathrm{m}^{2}\right)$

$a \quad$ Constant (0.36), equation 4

$b \quad$ Constant (0.08), equation 4

CCSGSP Closed cycle salt gradient solar pond

$C_{s} \quad$ Humid heat capacity of $(\mathrm{kJ} / \mathrm{kg} \mathrm{K})$

$c_{p l} \quad$ Heat capacity of water in the $\mathrm{LCZ}(\mathrm{J} / \mathrm{kg} \mathrm{K})$

$c_{p u} \quad$ Heat capacity of water in the UCZ (J/kg K)

$\mathrm{D}_{\mathrm{g}} \quad$ Distance between the bottom insulation and the water table $(\mathrm{m})$.

$\mathrm{D}_{\mathrm{i}} \quad$ Thickness of the bottom insulation(m)

E Pond's efficiency

EP evaporation pond

$F_{r} \quad$ Refraction parameter

$H \quad$ Solar radiation $\left(\mathrm{W} / \mathrm{m}^{2}\right)$

$h_{c} \quad$ Convective heat transfer coefficient to the air $\left(\mathrm{W} / \mathrm{m}^{2} \mathrm{~K}\right)$

$h_{x} \quad$ Fraction of solar radiation that reaches a depth $x\left(\mathrm{~W} / \mathrm{m}^{2}\right)$

$h_{o} \quad$ Heat transfer coefficient from outside wall surface to the atmosphere $\left(\mathrm{W} / \mathrm{m}^{2} \mathrm{~K}\right)$

$h_{1} \quad$ Heat transfer coefficient between the $\mathrm{NCZ}$ and the $\mathrm{UCZ}\left(\mathrm{W} / \mathrm{m}^{2} \mathrm{~K}\right)$

$h_{2} \quad$ Heat transfer coefficient between the $\mathrm{LCZ}$ and the $\mathrm{NCZ}\left(\mathrm{W} / \mathrm{m}^{2} \mathrm{~K}\right)$

$h_{3} \quad$ Heat transfer coefficient between the LCZ with surface at the bottom of the pond $\left(\mathrm{W} / \mathrm{m}^{2} \mathrm{~K}\right)$

$h_{4} \quad$ Heat transfer coefficient at the surface of the ground water sink $\left(\mathrm{W} / \mathrm{m}^{2} \mathrm{~K}\right)$

$k_{g} \quad$ Thermal conductivity of the soil under the pond $(\mathrm{W} / \mathrm{m} \mathrm{K})$

$k_{w} \quad$ Thermal conductivity of water $(\mathrm{W} / \mathrm{m} \mathrm{K})$

$k_{1} \quad$ Thermal conductivity of the first layer of insulation $(\mathrm{W} / \mathrm{m} \mathrm{K})$

$k_{2} \quad$ Thermal conductivity of polystyrene (W/m K)

$k_{3} \quad$ Thermal conductivity of wood $(\mathrm{W} / \mathrm{m} \mathrm{K})$

LCZ Lower convective zone

$l_{1} \quad$ Thickness of the first layer of insulation (m) 


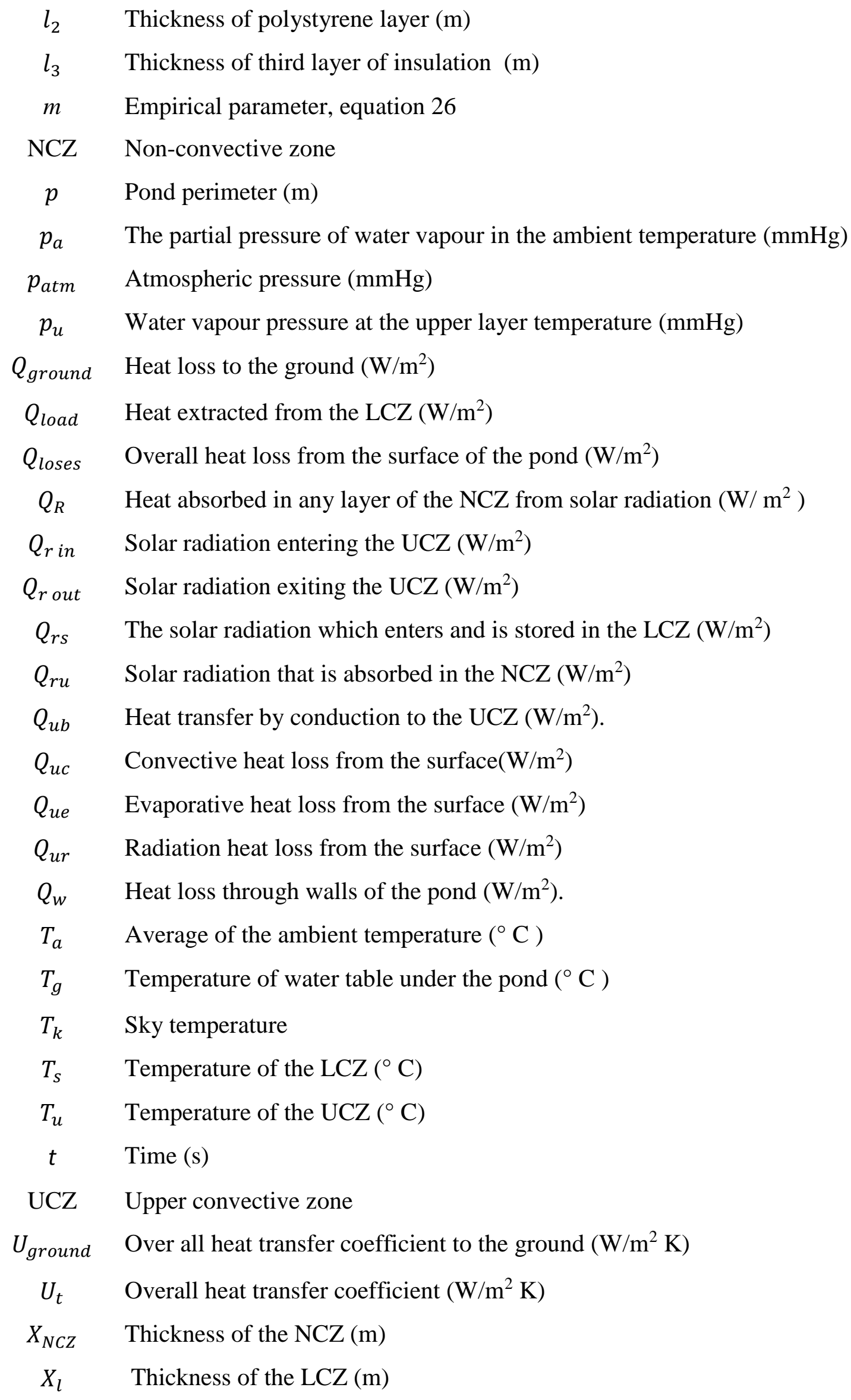

UCZ Upper convective zone

$U_{\text {ground }}$ Over all heat transfer coefficient to the ground $\left(\mathrm{W} / \mathrm{m}^{2} \mathrm{~K}\right)$

$U_{t} \quad$ Overall heat transfer coefficient $\left(\mathrm{W} / \mathrm{m}^{2} \mathrm{~K}\right)$

$X_{N C Z} \quad$ Thickness of the NCZ (m)

$X_{l} \quad$ Thickness of the LCZ (m) 


$$
\begin{array}{ll}
X_{u} & \text { Thickness of the UCZ }(\mathrm{m}) \\
x_{g} & \text { Distance of water table from pond's bottom }(\mathrm{m}) \\
x & \text { Thickness of water layer }(\mathrm{m}) \\
& \text { Greek letters } \\
\epsilon & \text { Emissivity of water } \\
\rho_{l} & \text { Density of the LCZ } \\
\rho_{u} & \text { Density of the UCZ }\left(\mathrm{kg} / \mathrm{m}^{3}\right) \\
v & \text { Monthly average wind speed in the region of study }(\mathrm{m} / \mathrm{s}) \\
\lambda & \text { Latent heat of vaporisation }(\mathrm{kJ} / \mathrm{kg}) \\
\gamma_{h} & \text { Relative humidity } \\
\sigma & \text { Stefen }- \text { Boltzmann's constant }\left(5.673 \times 10^{-8} \mathrm{~W} / \mathrm{m}^{2} \mathrm{~K}^{4}\right)
\end{array}
$$

\section{Introduction}

36 Scientists are worried about the high levels of pollutants and they are seeking alternative sources of energy. The best alternatives to the traditional sources of energy are renewable energies; they are clean and have sustainable resources. Many different types of these energies have been used, such as wind energy, bio-energy and solar energy. Solar ponds were discovered as a natural phenomenon in Transylvania by Kalecsinsky when he presented measurements on Lake Medve. The temperature in summer was around $60{ }^{\circ} \mathrm{C}$ at a depth of $1.3 \mathrm{~m}$; the sodium chloride concentration at the bottom was found to be near saturation. Interestingly, there was fresh water in the surface layer. Kalecsinsky concluded that artificial solar ponds might be useful for heat collection and storage. Significant research effort began in the 1960's, mostly concerned with generating electricity using the heat from the ponds (Nielsen, 1975). In 1977, a $1500 \mathrm{~m}^{2}$ pond was constructed to generate $6 \mathrm{~kW}$ of electricity by a turbine operating a Rankine cycle. A pond of area $6250 \mathrm{~m}^{2}$ in Ein Boqeq was built in the same year to generate $150 \mathrm{~kW}$ of electricity (Weinberg and Doron, 2010). In 1983, the El Paso solar pond was established and it has been in operation since 1985 (Alenezi, 2012). Currently, the research on the El Paso pond is focused on coupled desalination and brine management and enhancement of the techniques of solar pond operation and maintenance (Benjamin Schober, 2010, Huanmin et al 2004). There are two types of solar ponds, (i) convective and (ii) non-convective ponds (Alrowaished et al, 2013). A simple diagram (figure 1) can be drawn to demonstrate the types of solar ponds. 


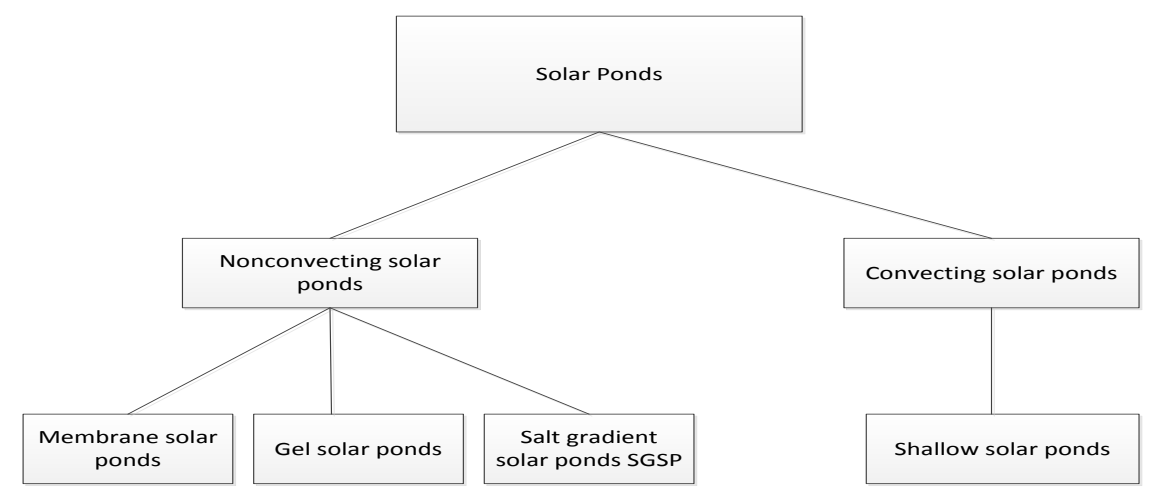

Figure 1 diagram showing the different classifications and types of solar ponds

A typical convecting solar pond is the shallow solar pond. Abdelsalam (1985) described a shallow pond comprised a plastic bag made from PVC, which is clear at the top and black at the bottom to absorb radiation. A shallow solar pond has a maximum depth of $15 \mathrm{~cm}$ (Garg, 1987). In convective solar ponds there is no insulating zone to prevent heat losses by convection. The pond is operated under normal atmospheric conditions (Anderson, 1980).

There are several types of non-convecting solar ponds. The most important type is the salt gradient solar pond (SGSP). A salt gradient solar pond is a body of water with a depth between 2-5 m and a gradient of salt concentration (Leblanc et al, 2011). To prevent natural convection, salty solution is used in the SGSP. The non convecting zone (NCZ) has a salinity gradient with the salinity increasing from the top to the bottom of the layer (Velmurugan and Srithar, 2008). This will supress, or decrease heat loss by natural convection which would be expected in fresh water. When a particular layer in the NCZ is heated, its density will decrease, but will remain higher than the layer above due to the salinity gradient. Consequently, upward movement due to buoyancy will stop, and heat can only move by conduction, from the lower layer to the top, through the NCZ (Date and Akbarzadeh, 2013). Solar ponds can take any geometrical shape. There are square, rectangular or circular cross section ponds, and the walls can also be vertical or sloping. However, a trapezoidal shape is often preferred and it is shown in figure 2.

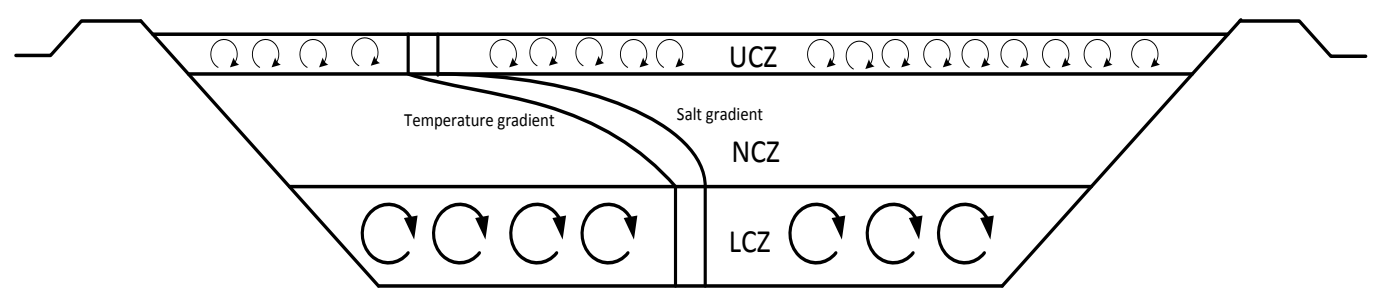

Figure 2 the most common shape of solar pond (Leblanc et al., 2011). 
Alternatives to the SGSP, which replace the insulating effect of the NCZ with either a transparent gel layer (Wilkins et al, 1982; Wilkins and Lee, 1987), or a transparent membrane (Hull, 1980) have been proposed. These alternatives have, however, received much less attention than the SGSP. In all cases, the heat from the pond can be used effectively in space heating, domestic and low temperature applications.

\section{Previous theoretical models}

Kooi (1979) developed a model to describe the SGSP. The steady state heat conduction equation was used to calculate the vertical temperature distribution, and an expression for the heat collected in the pond was developed. Many assumptions were adopted in the model. Firstly, it was considered that the pond's walls are vertical and well insulated. The base was also assumed to be well insulated. Secondly, the UCZ and LCZ were considered uniform with constant temperature and $k_{w}$ were held constant. Thirdly, the temperature of the UCZ zone was assumed to be close to the ambient temperature. Finally, the temperature was assumed to change only in the vertical direction.. It was concluded that if the NCZ is thin the heat loss will be large and that will affect the efficiency of the pond. On the other hand, if it is very thick, that will decrease the amount of insolation which reaches the LCZ significantly.

Wang and Akbarzadeh (1983) used the same steady state heat conduction equation with a slight modification. They allowed the ground temperature below the bottom of the pond at a depth of $\left(D_{i}+D_{g}\right)$ to be equal to the average ambient temperature $\left(\mathrm{T}_{a}\right)$. The heat loss to the ground was therefore taken into account in this model with two different types of soil below the pond. The value of the refraction parameter $F_{r}$ was considered to be constant $(0.85)$ by Wang and Akbarzadeh (1983) in their model. Wang and Akbarzadeh (1983) defined the efficiency of the pond as:

$$
E=\frac{q}{H}
$$

It was observed that, if the thickness of the UCZ is decreased from 0.2 to $0.1 \mathrm{~m}$, the efficiency will increase from 18.5 to $19.7 \%$. On the other hand, if it reaches $0.5 \mathrm{~m}$, the efficiency will drop to $15.5 \%$. It was also noticed that the efficiency increases with the increase of depth of the LCZ until a maximum value is reached. Thus, a further increase will lead to the efficiency declining. Consequently, it was recommended (Wang and Akbarzadeh, 1983) that the UCZ should be kept as thin as possible and the LCZ depth should be varied depending on the desired operating temperature, to achieve the maximum efficiency. Alagao et al. (1994) discussed a closed cycle salt gradient solar pond (CCSGSP) with details. The surface water was flushed to an evaporation pond (EP), in this pond; the water solution was 
concentrated and re-injected at the bottom of the solar pond. It was concluded that construction a CCSGSP depends on the net of evaporation and cost of salt and land. Alagao (1996) described the transient behaviour of solar pond with complete salt recycling system. The results showed (Alagao (1996) that area of the evaporation pond in a CCSGSP operation was affected by the rate of salt transport throughout the solar pond. In recent years, other models have been developed; most of them were solved numerically. For example, Jaefarzadeh, (2004) used a Crank-Nicolson scheme to solve the equations. Satisfactory results were achieved in the prediction of the temperature of the LCZ. Moreover, Andrews and Akbarzadeh, (2005), investigated an alternative method of heat extraction from the SGSP; they studied heat extraction from the gradient layer (NCZ). It was concluded that heat extraction from the NCZ has the potential to increase the efficiency of the SGSP compared with the method of heat extraction from the LCZ only. Another model has been suggested by Date et al (2013). A one-dimensional finite difference was used to solve the equations for the temperature development of the SGSP, with and without heat extraction. Safwan et al (2014) also used the one-dimensional finite difference to solve mass and heat equations which were derived in their model.

\section{Proposed model}

In the present study, a model for a SGSP has been developed to solve the non-linear first order differential equations for conservation of energy. It depends on the ode45 MATLAB function which uses a modified $4^{\text {th }}$ order Runge-Kutta numerical method with variable time stepping in the solution. Several assumptions have been adopted. Firstly, the pond consists of three zones; (i) the upper convective zone which contains approximately fresh water, (ii) the non-convective zone which has a gradual variation in salt concentration from top to bottom, and finally, (iii) the lower convective zone, where the concentration of salt is very high (about $0.26 \mathrm{~kg} / \mathrm{l}$ ). Secondly, both the UCZ and LCZ are considered well mixed. Thirdly, the solar radiation which reaches the LCZ is totally absorbed in this layer and heat accumulation in the NCZ has been neglected in the calculation of temperatures in the LCZ and UCZ. Finally, the solar insolation data from NASA has been considered and the value of refractive index $F_{r}=0.85$ as was taken by Wang and Akbarzadeh (1983).

\subsection{Upper convective zone (UCZ)}

The upper convective zone of the pond is represented schematically in Figure 3. 


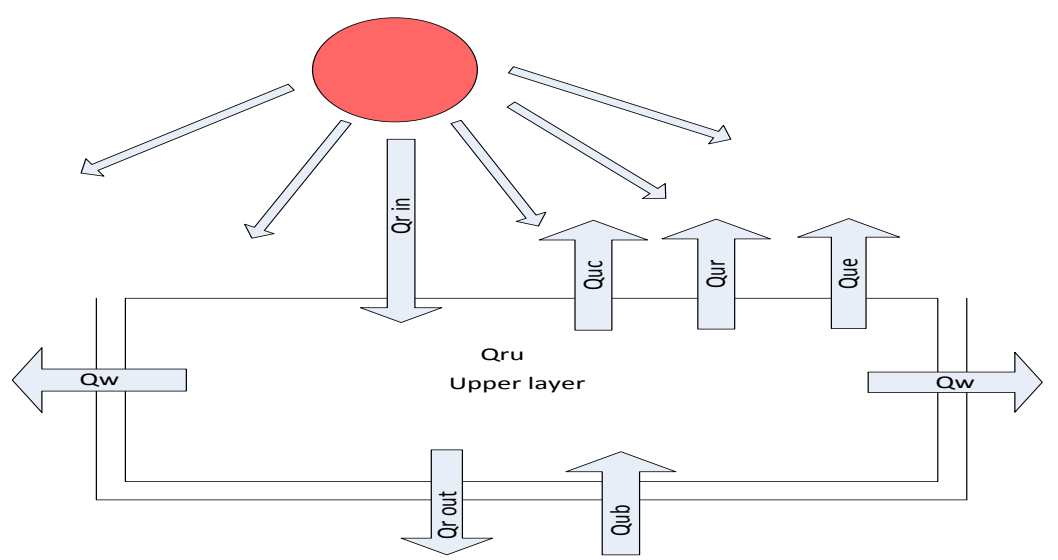

Figure 3 Heat balance on upper layer

The heat conservation equation is given as:

$$
\rho_{u} c_{p u} A_{u} X_{u} \frac{d T_{u}}{d t}=Q_{r u}+Q_{u b}-Q_{u c}-Q_{u r}-Q_{u e}-Q_{w}
$$

The left hand side of equation 2 represents the useful heat accumulated in the upper convective zone. For the right hand side of the equation, $Q_{w}$ is the heat loss through walls of the pond. In this work $Q_{w}=0$ (i.e. it is supposed that walls are well insulated), $Q_{r u}$ is the solar radiation that is absorbed through the upper layer. It can be calculated as:

$$
Q_{\text {ru }}=Q_{\text {rin }}-Q_{\text {rout }}
$$

where $Q_{r i n}$ is the incident solar radiation on the pond's surface $(H)$ and $Q_{r \text { out }}$ represents the solar radiation which comes out the UCZ. The value of $Q_{r u}$ changes with time and varies with pond location. The incident radiation can be directly recorded from climatological data for any place, and it also can be calculated. In the present study data from NASA has been considered (NASA, 2014). Some of the incident sunlight reflects back to the sky and the rest of solar radiation is absorbed by the water body. Rabl and Nielsen (1975) claim that the absorption of solar radiation through a body of water cannot be described by a simple exponential. They determined the absorption coefficients and fractions of solar radiation for each of four bands. An alternative, simpler formula was suggested by Bryant and Colbeck (1977) as:

$$
h_{x}=H(a-b \ln x)
$$

where $a=0.36, b=0.08, x$ is the thickness of water layer in meters and it is valid from 0.01 $-10 \mathrm{~m}$ water depth, and $h_{x}$ is the solar radiation in any depth of water. That means

$$
h_{x}=H(0.36-0.08 \ln x)
$$

Equation 5 has been used to compute the absorption solar radiation in the water body in this work, thus 


$$
Q_{r u}=H\left(1-0.36+0.08 \ln X_{u}\right)
$$

167 The heat transfer to the UCZ by conduction from the LCZ is calculated by using the 168 following equation:

$$
Q_{u b}=U_{t} A_{u}\left[T_{s}-T_{u}\right]
$$

170 Here, $T_{u}$ and $T_{s}$ are the temperatures of the UCZ and the LCZ respectively, and $U_{t}$ is the overall heat transfer coefficient, which can be computed as:

$$
U_{t}=\frac{1}{R_{\text {total }}}=\frac{1}{\frac{1}{h_{1}}+\frac{X_{N C Z}}{k_{W}}+\frac{1}{h_{2}}}
$$

173 In the equation above, $h_{1}$ and $h_{2}$ are the convective heat transfer coefficient between the NCZ and the UCZ, and between the LCZ and the NCZ. Their values are 56.58 and $48.279 \mathrm{~W} / \mathrm{m}^{2}$ $175 \mathrm{~K}$, respectively. The thermal conductivity of water $\left(k_{w}\right)$ is $0.596 \mathrm{~W} / \mathrm{m} \mathrm{K}$ (Bansal and 176 Kaushik, 1981). The values of heat transfer coefficients were calculated theoretically by 177 Bansal and Kaushik (1981).

Equation 7 can therefore be written as:

$$
Q_{u b}=\frac{A_{u}\left[T_{s}-T_{u}\right]}{\frac{1}{h_{1}}+\frac{X_{N C Z}}{K_{w}}+\frac{1}{h_{2}}}
$$

$$
Q_{\text {loses }}=Q_{u c}+Q_{u r}+Q_{u e}
$$

Heat loss by convection $\mathrm{Q}_{\mathrm{uc}}$ is given as:

$$
Q_{u c}=h_{c} A_{u}\left[T_{u}-T_{a}\right]
$$

Here $h_{c}$ is the convective heat transfer coefficient from the water surface to the air in $\mathrm{W} / \mathrm{m}^{2}$ $\mathrm{K}$ and it is calculated by using a formula which was introduced by McAdams (1954) as:

$$
h_{c}=5.7+3.8 v
$$

where $v$ is the average wind speed.

Radiation heat loss can be calculated as:

$$
Q_{u r}=\sigma \epsilon A_{u}\left(T_{u}^{4}-T_{k}^{4}\right)
$$

where $\sigma$ is the Stefen -Boltzmann's constant, $\epsilon$ is the emissivity of water $=0.83$ (Safwan et al, 2014), and $T_{k}$ is the sky temperature. It is calculated as:

$$
T_{k}=0.0552 T_{a}^{1.5}
$$

Finally, the heat loss from the surface by evaporation $\left(Q_{u e}\right)$ is given by Kishore and Joshi (1984) as:

$$
Q_{u e}=\left\{\frac{\left[\lambda h_{c}\left(p_{u}-p_{a}\right)\right]}{\left[\left(1.6 C_{s} p_{a t m}\right)\right]}\right\} A_{u}
$$


197

217 It is assumed to begin with that there is no load i.e. $Q_{l o a d}=0$. This corresponds to the initial 218

where $C_{s}$ is the humid heat capacity of air in $\mathrm{kJ} / \mathrm{kg}$. K given by:

$$
C_{s}=1.005+1.82 \gamma_{h}
$$

The symbol $\mathrm{p}_{\mathrm{u}}$ is the water vapour pressure at the upper layer temperature in $\mathrm{mmHg}$ and it is calculated as:

$$
p_{u}=\exp \left[18.403-3885 /\left(T_{u}+230\right)\right]
$$

The partial pressure of water vapour in the ambient temperature in $\mathrm{mmHg}$ is represented by $\mathrm{p}_{a}$ and it is calculated as:

$$
p_{a}=\gamma_{h} \exp \left[18.403-3885 /\left(T_{a}+230\right)\right]
$$

Equation 2 which represents energy conservation in the UCZ can therefore be rewritten as:

$\rho_{u} c_{p u} A_{u} X_{u} \frac{d T_{u}}{d_{t}}=A_{u}\left[Q_{r u}+\frac{\left[T_{s}-T_{u}\right]}{\frac{1}{h_{1}}+\frac{X_{N C Z}}{K_{w}}+\frac{1}{h_{2}}}-\left\{(5.7+3.8 v)\left[T_{u}-T_{a}\right]\right\}-4.708 \times 10^{-8}\left\{T_{u}^{4}-\right.\right.$

$$
\left.\left.\left[0.0552\left(T_{a}\right)^{1.5}\right]^{4}\right\}-\left[\lambda h_{c}\left(p_{u}-p_{a}\right)\right] /\left[\left(1.6 C_{s} p_{a t m}\right)\right]\right]
$$

\section{There are two variables in equation 19, i.e. $T_{u}$ and $T_{s}$. Another equation with the same} variables is required to find values of the unknowns. A conservation equation for energy in the storage or lower convective zone (LCZ) must also be defined.

\subsection{Lower convective zone (LCZ)}

The heat balance on the LCZ is illustrated in figure 4 .

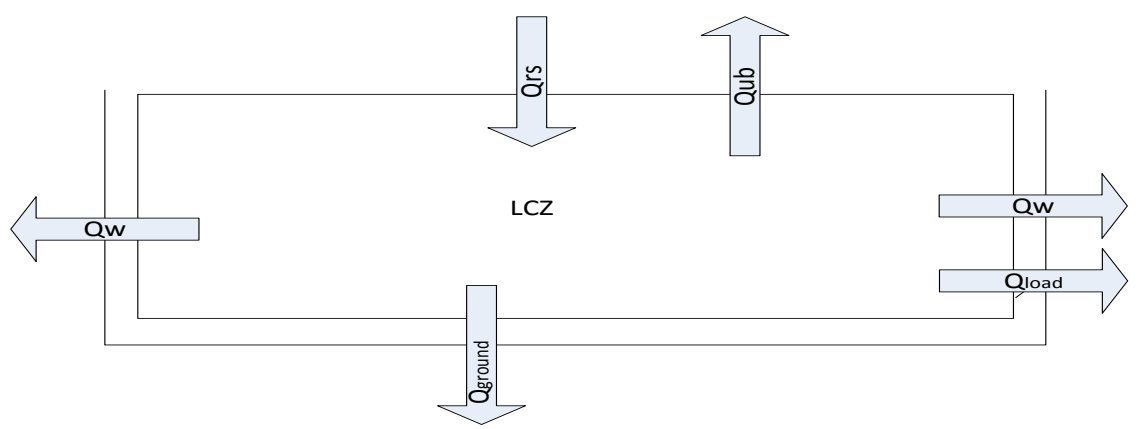

Figure 4 heat balance on lower convective zone (storage zone).

A heat balance on the LCZ is given as:

$$
\rho_{l} c_{p l} A_{l} X_{l} \frac{d T_{s}}{d t}=Q_{r s}-Q_{u b}-Q_{g r o u n d}-Q_{\text {load }}-Q_{w}
$$
warming period of the pond. In addition, it is assumed that $Q_{w}=0$ i.e. it is supposed that walls are well insulated. Equation 20 can be rewritten as:

$$
\rho_{l} c_{p l} A_{l} X_{l} \frac{d T_{s}}{d t}=Q_{r s}-Q_{u b}-Q_{\text {ground }}
$$


221 The solar radiation which enters and is stored in the LCZ $\left(Q_{r s}\right)$ can be computed by using equation 5 , and in this case:

$$
Q_{r s}=H_{L C Z}=H\left(0.36-0.08 \ln \left(X_{u}+X_{N C Z}\right)\right.
$$

224 Heat which moves upward from the LCZ $\left(Q_{u b}\right)$, can be calculated from equation 9. This is considered to be the same as the heat that moves to the UCZ

226 To calculate $Q_{\text {ground }}$, the equation is:

$$
Q_{\text {ground }}=U_{\text {ground }} A_{b}\left(T_{s}-T_{g}\right)
$$

The overall heat transfer coefficient to the ground is given as:

$$
U_{\text {ground }}=\frac{1}{R_{3}+R_{g}+R_{4}}
$$

230 The symbols $R_{3}, R_{g}$ and $R_{4}$ represent the resistances to heat transfer to the ground.

$$
R_{3}=\frac{1}{h_{3}}, R_{g}=\frac{x_{g}}{k_{g}}, R_{4}=\frac{1}{h_{4}}
$$

232 Here $h_{3}$ is the convective heat transfer coefficient at the boundary between the storage zone and the surface at the bottom of the pond in $\mathrm{W} / \mathrm{m}^{2} \mathrm{~K}, h_{4}$ is the convective heat transfer coefficient at the surface of the ground water sink. Their values are 78.12 and $185.8 \mathrm{~W} / \mathrm{m}^{2} \mathrm{~K}$ respectively (Sodha et al, 1980). They were calculated theoretically by the researchers from the standard expressions of McAdams (1954). Equation 23 becomes:

$$
Q_{\text {ground }}=\frac{A_{b}\left(T_{s}-T_{g}\right)}{\frac{1}{h_{3}}+\frac{x_{g}}{k_{g}}+\frac{1}{h_{4}}}
$$

238

239

Hull et al (1984) claim that heat loss from any pond to the ground is a function of both perimeter and area of the pond. It also depends on the conductivity of the soil and distance to the water table beneath the pond. Their conclusion was based on many experiments and numerical simulations. Hull et al (1988) assumed that the temperature of the water table under the pond is constant and proposed a new equation to model this transfer.

$$
U_{\text {ground }}=\frac{k_{g}}{x_{g}}+m k_{g} \frac{p}{A_{u}}
$$

The value of empirical parameter $(m)$ varies depending on whether the walls of the pond are vertical or inclined. Equation 23 can be re-written including this formulation as:

$$
Q_{\text {ground }}=\left\{\left(\frac{k_{g}}{x_{g}}+m k_{g} \frac{p}{A_{u}}\right) A_{b}\left(T_{s}-T_{g}\right)\right\}
$$

In the present study another case for the pond has been considered. It is supposed that the pond is unburied; i.e. it is above ground with a space between it and the ground. It is suggested that bottom of the pond consists of three layers, two layers of wood and a layer of polystyrene between. In this situation $U_{\text {ground }}$ can be given as. 


$$
U_{\text {ground }}=1 /\left[\left(\frac{1}{h_{3}}\right)+\left(\frac{l_{1}}{k_{1}}\right)+\left(\frac{l_{2}}{k_{2}}\right)+\left(\frac{l_{3}}{k_{3}}\right)+\left(\frac{1}{h_{o}}\right)\right]
$$

252 In equation 28, $l_{1}, k_{1}$ are the thickness and thermal conductivity of the first layer of 253 insulation(wood). Their values are $0.01 \mathrm{~m}$ and $0.13 \mathrm{~W} / \mathrm{m} \mathrm{K}$ respectively. Similarly, $l_{2}, \mathrm{k}_{2}$ are the thickness and thermal conductivity for the second layer of insulation (polystyrene). Their values are $0.06 \mathrm{~m}$ and $0.03 \mathrm{~W} / \mathrm{m} \mathrm{K}$ respectively. Finally, $l_{3}, \mathrm{k}_{3}$ are the thickness and thermal conductivity for the third layer of insulation .Their values are similar to $l_{1}$ and $\mathrm{k}_{1}$. The heat transfer coefficient from the outside surface to the atmosphere $\left(h_{o}\right)$ is taken as $5.43 \mathrm{~W} / \mathrm{m}^{2} \mathrm{~K}$.

258 Equation 23 will be.

259

$$
Q_{\text {ground }}=\left[\frac{1}{\left[\left(\frac{1}{h_{3}}\right)+\left(\frac{l_{1}}{k_{1}}\right)+\left(\frac{l_{2}}{k_{2}}\right)+\left(\frac{l_{3}}{k_{3}}\right)+\left(\frac{1}{h_{o}}\right)\right]}\right] A_{b}\left(T_{s}-T_{a}\right)
$$

Equation 20 can be rewritten as.

$$
\rho_{l} c_{p l} A_{l} X_{l} \frac{d T_{s}}{d t}=A_{l}\left[Q_{r s}-\frac{\left[T_{s}-T_{u}\right]}{\frac{1}{h_{1}}+\frac{X_{N C Z}}{K_{W}}+\frac{1}{h_{2}}}-Q_{\text {load }}\right]-\frac{A_{b}\left(T_{s}-T_{g}\right)}{\frac{1}{h_{3}}+\frac{x_{g}}{k_{g}}+\frac{1}{h_{4}}}
$$

262

Hence, three different expressions have been used in equation 30 to represent $Q_{\text {ground }}$. For three or four months $Q_{\text {load }}$ can be neglected to give the pond time to warm up.

\section{Results and discussion}

Equations 19 and 30 have been solved by using MATLAB. Three different formulae for $Q_{\text {ground }}$ were used and different results have been observed. By this method equations 19 and 30 can be solved depending on the initial values of the unknown temperatures $T_{u}$ and $T_{s}$. These initial values vary with the location of the pond and the time of year when the pond starts working. The values of the constants which are used in the model are as follows $\rho_{u}=$ $1000 \mathrm{~kg} / \mathrm{m}^{3}, \quad \rho_{l}=1200 \mathrm{~kg} / \mathrm{m}^{3} \quad c_{p u}=4180 \mathrm{~J} / \mathrm{kg} \mathrm{K}, \quad c_{p l}=3300 \mathrm{~J} / \mathrm{kg} \mathrm{K}, A_{u}=A_{l}=$ $A_{b}=1 \mathrm{~m}^{2}, h_{1}=56.58, h_{2}=48.279, h_{3}=78.12, h_{4}=185$ (all values in $\mathrm{W} / \mathrm{m}^{2} \mathrm{~K}$ ) and $k_{w}=0.596 \mathrm{~W} / \mathrm{m} \mathrm{K}, T_{g}=23^{\circ} \mathrm{C}$. The value of $x_{g}$ and $k_{g}$ depends on the soil properties under the pond, for example their values in El Paso pond in the USA are different from values for Ein Boqeq pond in Israel. The effect of evaporation, radiation and convection on the pond has been investigated, and values of solar radiation can be changed according to the location. The pond is first considered to be in Kuwait to compare results with available experimental data for this city. The climatic conditions for Kuwait City are listed in table 1. 0

(1)


Table1 climatic conditions of Kuwait city (NASA, 2014)

\begin{tabular}{|l|c|c|c|c|}
\hline Month & $\begin{array}{l}\text { Solar radiation } \\
\mathrm{MJ} / \mathrm{m}^{2} . \mathrm{month}\end{array}$ & $\begin{array}{l}\text { Ambient } \\
\text { temperature }{ }^{\circ} \mathrm{C}\end{array}$ & $\begin{array}{l}\text { Relative humidity, } \\
\%\end{array}$ & $\begin{array}{l}\text { Wind speed } \\
\mathrm{m} / \mathrm{s}\end{array}$ \\
\hline January & 345.6 & 12.6 & 53.6 & 3.3 \\
\hline February & 456.84 & 14.6 & 43.7 & 3.5 \\
\hline March & 545.4 & 19.1 & 37.9 & 3.7 \\
\hline April & 630.72 & 25.9 & 29 & 3.4 \\
\hline May & 757.08 & 32 & 20.4 & 4.1 \\
\hline June & 852.12 & 35.7 & 15.3 & 4.5 \\
\hline July & 825.12 & 37.6 & 15.2 & 4.2 \\
\hline August & 770.04 & 37.2 & 17.4 & 4.1 \\
\hline September & 665.28 & 33.6 & 20.6 & 3.7 \\
\hline October & 509.76 & 28.1 & 30.1 & 3.3 \\
\hline November & 349.92 & 20.5 & 43.2 & 3.4 \\
\hline December & 286.2 & 14.7 & 51.5 & 3.4 \\
\hline average & 514.08 & 25.96 & 31.49 & 3.7 \\
\hline
\end{tabular}

283

It is beneficial to plot the profile of the incident solar radiation in the location of the pond to observe its behaviour during the year. The radiation profile can help to observe easily the changes in the radiation throughout the year and to identify when it is high or low. The profile appears in figure 5 for Kuwait City.

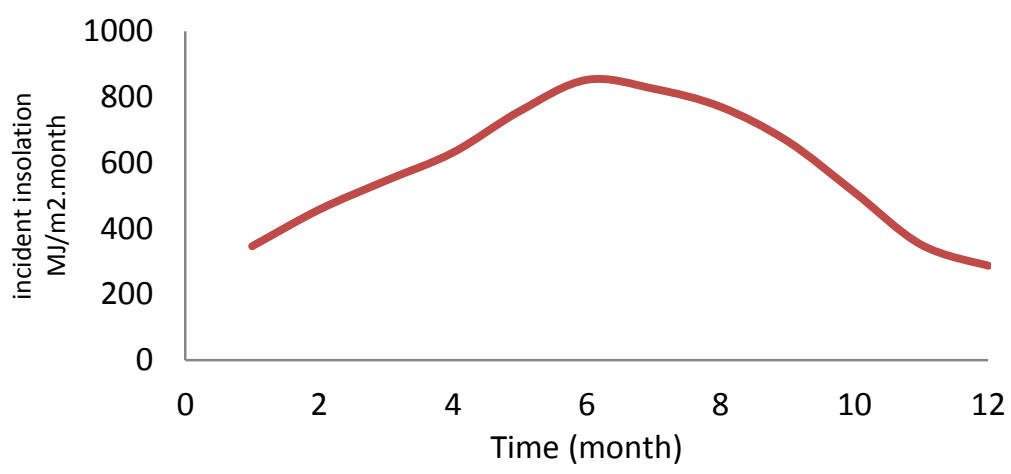

Figure 5 profile solar radiation of Kuwait City during one year

It is clear from figure 5 that the incident solar radiation on this city increases gradually from the winter to the summer season and it reaches the maximum value in June. There is clearly a 
293

294

295

296

297

298

299

300

301

302

303

304

305

306

307

308

309

310

311

312

313

314

315

316

317

318

319

very large seasonal range in the insolation, which will significantly affect the behaviour of the pond.

\subsection{Validation of the model}

\subsubsection{Kuwait City}

To examine the validity of the model, the computed temperature of the LCZ is compared with the experimental data of Ali (1986) for a pond in Kuwait city (There was no heat extraction from the pond). The dimensions of the Kuwait pond were $4 \times 2 \times 0.9 \mathrm{~m}$ and the depth of layers was $0.2,0.4$ and $0.3 \mathrm{~m}$ for UCZ, NCZ and LCZ respectively. This comparison is shown in figure 6.

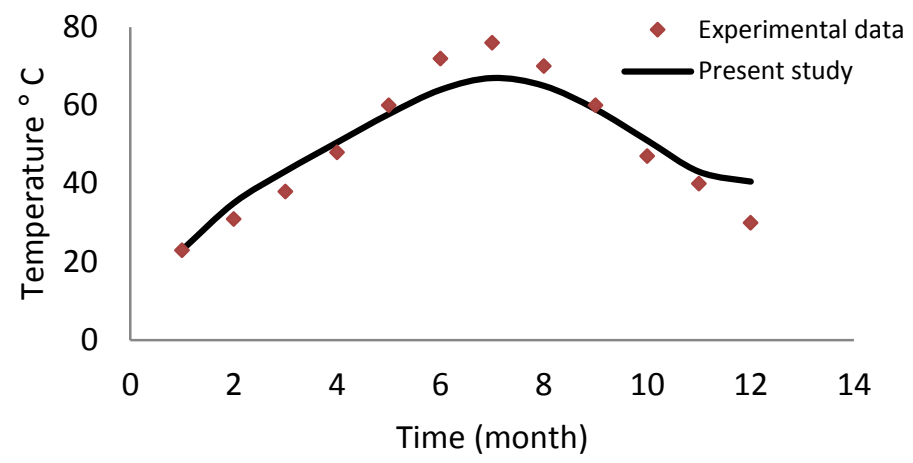

Figure 6 validation of temperature distribution of the LCZ of the present model with experimental data for Kuwait City (initial temperatures are 14 and $23^{\circ} \mathrm{C}$ for the UCZ and LCZ respectively).

There is a good agreement between the model and experimental data for the temperature in the storage zone. A slight variation in temperatures of the LCZ is apparent. This variation might be due to the difference between real and assumed values of the heat transfer coefficients.

\subsubsection{El Paso}

The present model is also compared with experimental data from the El-Paso solar pond (1999), (with these experimental results there was also no load). The surface area of this pond is $3000 \mathrm{~m}^{2}$ and the depths of layers are 0.7, 1.2 and $1.35 \mathrm{~m}$ for UCZ, NCZ and LCZ respectively (Huanmin et al, 2001). The depth is large compared with the Kuwait solar pond. The climatic conditions of El Paso are shown in table 2 and the comparison is demonstrated in figure 7. 
320 Table 2 climatic conditions of El Paso, Texas (1999), (Huanmin et al, 2001)

\begin{tabular}{|l|c|c|c|c|}
\hline Month & $\begin{array}{l}\text { Solar radiation } \\
\mathrm{MJ} / \mathrm{m}^{2} \text {.month }\end{array}$ & $\begin{array}{l}\text { Ambient } \\
\text { temperature }{ }^{\circ} \mathrm{C}\end{array}$ & $\begin{array}{l}\text { Relative } \\
\text { humidity, } \%\end{array}$ & $\begin{array}{l}\text { Wind speed } \\
\mathrm{m} / \mathrm{s}\end{array}$ \\
\hline January & 378 & 6 & 51 & 3.2 \\
\hline February & 486 & 8.9 & 32 & 3.5 \\
\hline March & 637 & 12.8 & 27 & 4.4 \\
\hline April & 766 & 17.4 & 27 & 4.1 \\
\hline May & 842.4 & 22.1 & 30 & 3.5 \\
\hline June & 864 & 26.9 & 44 & 3.2 \\
\hline July & 799 & 27.9 & 48 & 3 \\
\hline August & 734 & 26.7 & 51 & 2.9 \\
\hline September & 637 & 23.6 & 47 & 2.8 \\
\hline October & 529 & 17.8 & 47 & 3.1 \\
\hline November & 410 & 11.3 & 52 & 3 \\
\hline December & 345 & 6.7 & 41.5 & 3.4 \\
\hline average & 618 & 17.3 & & \\
\hline
\end{tabular}

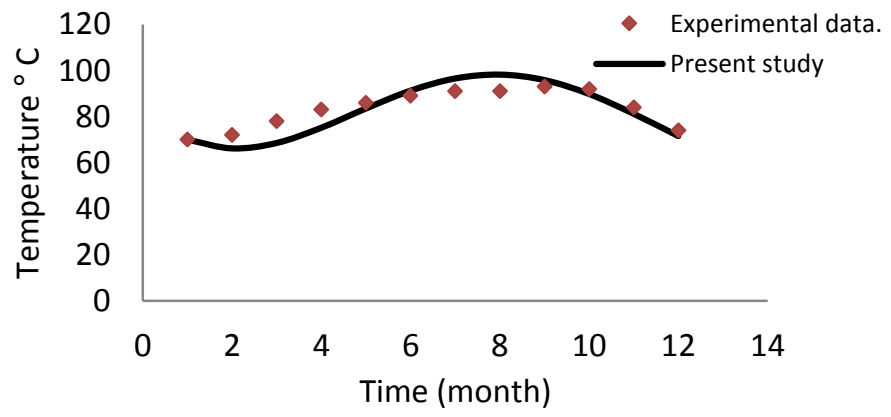

Figure 7 Comparison profiles of the LCZ temperature of the present model with El-Paso pond experimental data (1999) (initial temperatures are 6 and $70^{\circ} \mathrm{C}$ for UCZ and LCZ respectively).

The profile of the experimental measurement in the LCZ tends to show little variation in the temperature. This slight variation might be due to the high initial temperature because it has an effect on the behaviour of temperature in the LCZ. This effect has been discussed by many researchers e.g. Jaefarzadeh (2004) and (2005) and Madani (2014). It was concluded that the 
333

334

335

336

337

338

339

340

341

342

343

344

345

346

347

348

349

350

351

352

353

354

initial temperature has a slight effect on the LCZ temperature and after few months the difference in maximum temperature among cases with different initial temperatures becomes low. In other words, if two ponds start with two different temperatures for the LCZ with one of them being low and the other one high, then the temperature in the LCZ in the first one will increase while in the second one temperature will decrease slightly. Subsequently it will increase slowly as the radiation intensity increases. However, after few months the gap between the two temperatures will be small. As demonstrated in figure 7, for the model, the behaviour is approximately similar to the described behaviour because before May, the temperature decreases, after that it increases gradually. It reaches maximum value in August. A gradual decrease in temperature is seen after August to be close to the experimental results. The difference between the two values of temperatures becomes very small from September. The difference between the experimental data of the El Paso pond and theoretical values according to the present study may be because of the difference between theoretical and experimental heat transfer coefficient, but also the clarity of the pond because it was working for a long time prior to the measurements in 1999.

\subsection{Effect of ground heat loss}

The experimental data for the LCZ of Ali's (1986) pond in Kuwait is also compared with the present model, but by using equations 27 and 29 to represent heat loss to the ground, comparison is illustrated in figure 8 .

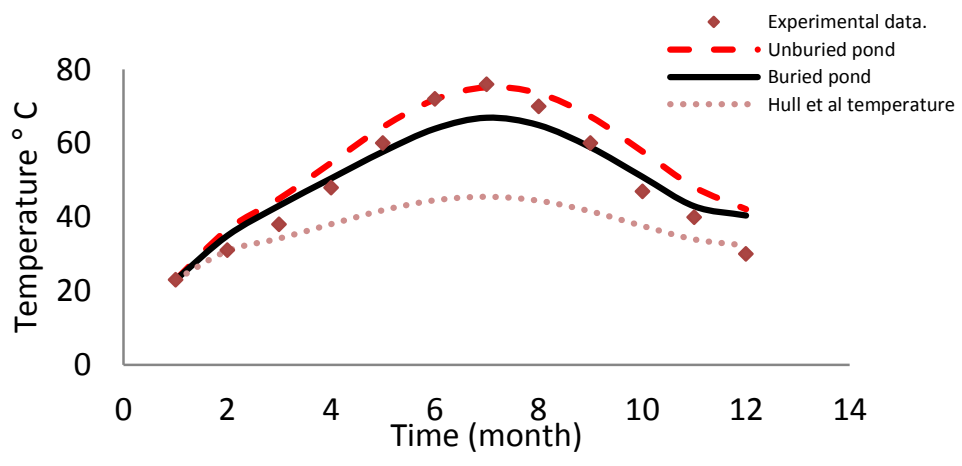

Figure 8 comparison of experimental temperature distribution of the lower layer LCZ of the Kuwait pond with unburied and Hull et-al (1988) formulae for heat loss to the ground.

It is apparent from figure 8 that in the case of an unburied pond (equation 29 has been used for $\left.Q_{\text {ground }}\right)$. The temperatures are higher than the experimental values for most of the year. This difference can be explained by two facts. Firstly, the buried pond in the present model loses heat to the ground because the shallow layers of soil have high thermal conductivity. 
Consequently, heat loss to the soil from the bottom of the pond (no heat loss from walls, as they are considered well insulated) is higher than in the unburied case and has an impact on the pond, causing a decrease in temperature. Secondly, the temperature of the air reaches more than $37^{\circ} \mathrm{C}$ in some areas, particularly in arid and desert places including Kuwait (table 2). In this situation heat loss to the atmosphere in the proposed unburied pond will be small as compared with the buried pond with continuous heat loss to the soil. The profile of the LCZ in the case of unburied pond gives an indication that this pond can reach a temperature higher than a buried pond during the year, particularly, in hot areas. However, new parameters will appear in this case and need to be tackled. An economic balance will be very helpful to evaluate the positive and negative factors. These factors can be discussed economically and experimental data can provide guide for this type of pond.

When heat loss to the ground is computed by applying the formula which is proposed by Hull et al (1988), it is obvious from figure 8 that the increases in temperature are slower than the experimental changes. The reason for this behaviour is probably the effect of perimeter because Hull et al consider it has high impact on the temperature of the pond. That effect can be observed from the formula of Hull et al (1988) in equation 26 for $U_{\text {ground }}$.

$$
U_{\text {ground }}=\frac{k_{g}}{x_{g}}+m k_{g} \frac{p}{A_{u}}
$$

The suggested formula illustrates mathematically that the second term has significant influence on the value of $U_{\text {ground }}$ for small ponds because the contribution of $\frac{p}{A_{u}}$ is important. In large ponds the influence of $\frac{p}{A_{u}}$ will decrease substantially. To investigate this situation, a pond of the same depth as the Kuwait pond $2 \times 4 \times 0.9 \mathrm{~m}$, but with different dimensions 30x100x0.9 $\mathrm{m}$ has modelled and compared with the small pond. The specifications of the two ponds are shown in table 3.

Table 3 small and large suggested pond specifications

\begin{tabular}{|c|c|c|c|}
\hline & Location & Dimensions $(\mathrm{m})$ & $\begin{array}{c}\text { Layer depth }(\mathrm{m}) \\
\text { UCZ,NCZ,LCZ }\end{array}$ \\
\hline Small pond & Kuwait & $4 \times 2 \times 0.9$ & $0.2,0.4,0.3$ \\
\hline Large pond & Kuwait & $30 \times 100 \times 0.9$ & $0.2,0.4,0.3$ \\
\hline
\end{tabular}

It is clear from table 3 that the difference between ponds is only in surface area and perimeter. The profiles of temperature for both ponds are demonstrated in figure 9. 


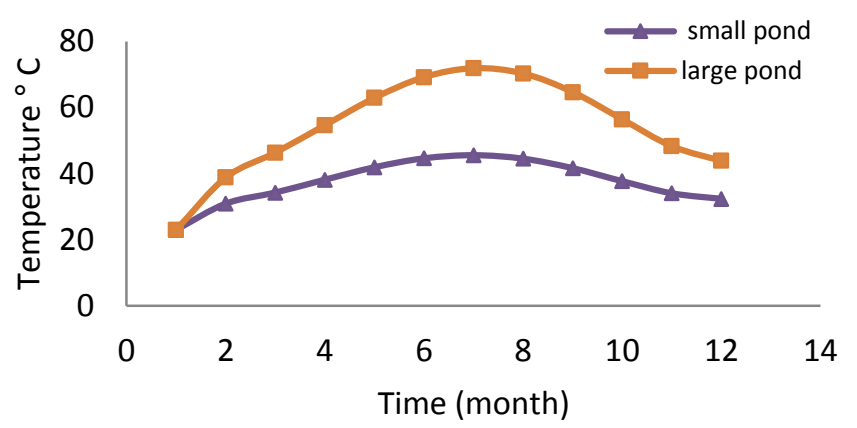

387

388 Figure 9 comparison of temperature distribution of lower layer (LCZ) between small and 389 large pond when formula of Hull et al (1988) is used.

390 Figure 9 demonstrates that temperature of the suggested large pond with $3000 \mathrm{~m}^{2}$ of surface 391 area and $260 \mathrm{~m}$ perimeter is much higher than the temperature of the small pond $8 \mathrm{~m}^{2}$ and 12 $392 \mathrm{~m}$ perimeter throughout the year. The shape of the pond can be significant because perimeter 393 changes with geometrical shape. The temperature can also increase by increasing the depth of 394 the pond because the selected layer's depth is small $(0.2,0.4,0.3) \mathrm{m}$ for UCZ, NCZ and LCZ 395 respectively.

396

397

4.3. Temperature distributions in suggested model pond

398

4.3.1. Temperature profiles in the UCZ and $L C Z$

399

The profiles of temperature for both upper and lower layers have been plotted for a pond with 400 dimensions of $1 \times 1 \times 1.5 \mathrm{~m}$ and thicknesses of $0.2,0.8$ and $0.5 \mathrm{~m}$ for the UCZ, NCZ and LCZ respectively. Once again the pond is assumed to be in Kuwait City. The profiles are shown in 402 figure 10 .

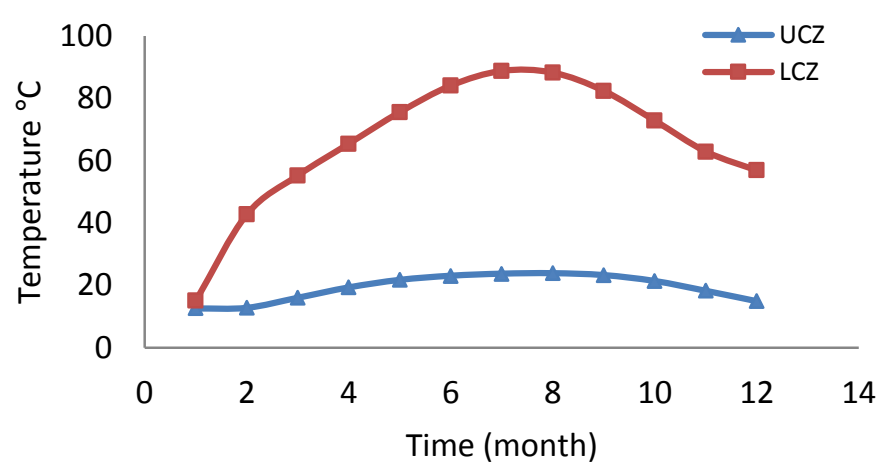

403

404 Figure 10 profile of temperature in LCZ and UCZ during one year (initial temperatures are $40512.6^{\circ} \mathrm{C}$ for both layers and month 1 is January).

406 It is obvious from figure 10 that the temperature of the lower layer increases substantially 407 with time to reach maximum values around $90{ }^{\circ} \mathrm{C}$ during July. After that the temperature 
decreases slightly with time to remain between 50 to $60{ }^{\circ} \mathrm{C}$ in December. The reason for this behaviour is that solar radiation incident on the pond also increases steadily in the first part of the year and it reaches the highest value in June. In the latter half of the year the radiation decreases. This behaviour can be seen apparently in figure 5. It is approximately clear from

412 figure 10 that the temperature of the $\mathrm{LCZ}$ is around $50-60{ }^{\circ} \mathrm{C}$ in the end of the year even with 413 cold weather in winter. This is due to the accumulation of heat. Moreover, heat loss from the 414 walls is neglected and that means the pond might remain warm for a long time. The variation 415 of upper layer temperature is small. This is as a consequence of heat exchange between water 416 surface and the surrounding air and that leads to the temperature of UCZ tending to the air 417 temperature. Similar behaviour has been observed by many researchers, e.g. Safwan et al 418 (2014), Alenezi (2011), Al-Jamal and Khashan (1998), Date et al (2013), Karakilcik et al 419 (2006), German and Muntasser (2008) and Jaefarzadeh (2005).

\section{4.3.2. Non-convective zone}

421 The temperatures of NCZ have also been calculated for every month by dividing the layer 422 into many layers. The thickness of every layer is chosen as $0.1 \mathrm{~m}$. Figure 11 shows the NCZ 423 layer.

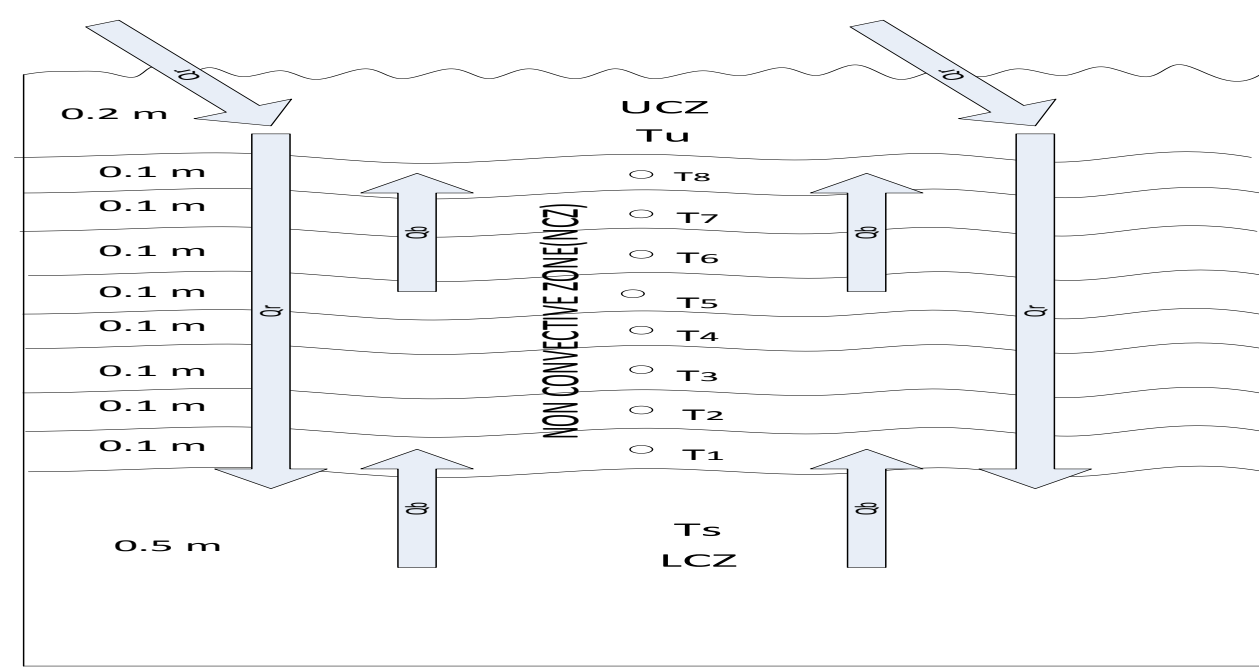

Figure $11 \mathrm{NCZ}$ section of the pond which shows the suggested partitions.

An energy balance on every layer in the NCZ layer can be written as:

$$
Q=K_{w} \frac{\partial T}{\partial x}+Q_{R}
$$

The energy transferred through the NCZ by conduction is computed by;

$$
Q=U_{t} \Delta T
$$


430 The overall heat transfer coefficient $U_{t}$ is calculated by applying equation 8 . The distribution 431 of temperature through the NCZ can be calculated for any month during the year and it can 432 be started form the upper or lower layer. The profile of temperature for the whole pond can 433 be drawn through any month of the year. It is illustrated in figure 12 for four months.

434

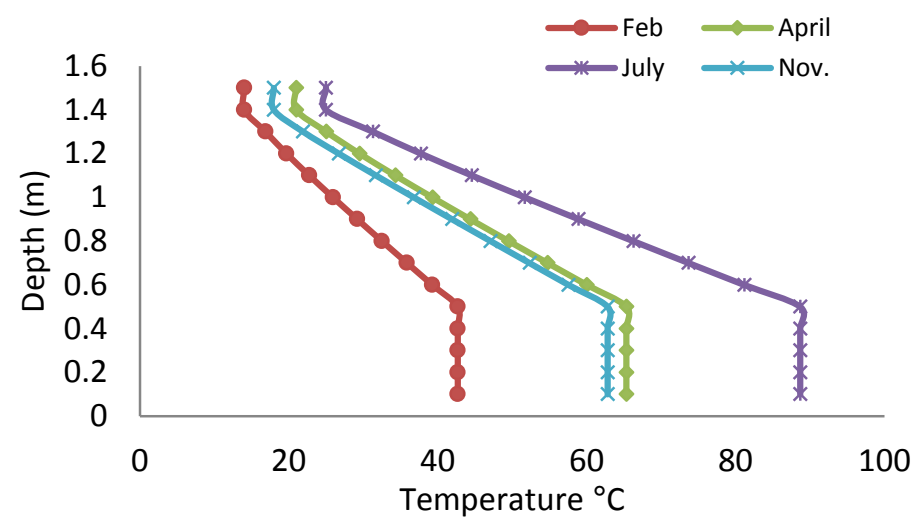

435 Figure 12 the distribution of temperature in the pond for four selected month, February, April 436 July and November

437 As shown from figure 12, temperature is constant in both upper and lower layer because the two layers are considered well mixed in the model. The temperature of the middle layer (NCZ) decreases gradually from the bottom to the top of the pond. The same behaviour is observed in both experimental and theoretical studies on the salt gradient solar pond. The

441 highest difference between temperature in the LCZ and UCZ is in July (more than $60{ }^{\circ} \mathrm{C}$ ) 442 whereas the lowest is in February (less than $30^{\circ} \mathrm{C}$ ).

\subsection{Surface heat loss}

445 The rate at which heat is lost from the surface of the pond obviously plays a significant role 446 in determining its performance. Three heat loss mechanisms operate in parallel, namely 447 radiation, convection and evaporation. To assess the importance of each of these 448 mechanisms, each was considered to occur in isolation. The effect of this mechanism for heat 449 loss on the performance of the pond could then be ascertained by inspection of the 450 temperatures reached in the pond. Firstly, evaporation and convection have been neglected to 451 observe the effect of radiation only. The same process is repeated for evaporation and 452 convection. It is appear that evaporation has the highest influence on both LCZ and UCZ 453 temperatures. In contrast radiation has the lowest effect on both temperatures. Convection has 

for the LCZ and UCZ respectively.

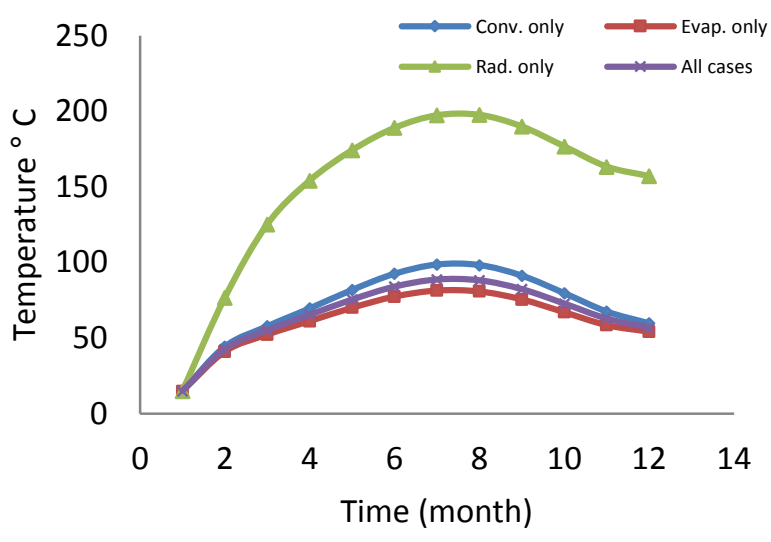

457 Figure 13 temperature of the LCZ with different cases of heat loss from the surface.

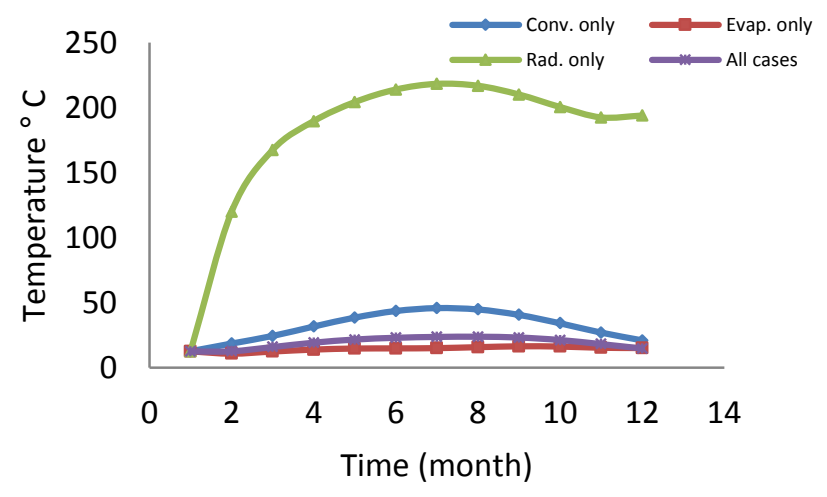

458

459 Figure 14 temperature of the UCZ with different cases of heat loss from the surface.

460 It is apparent from the two figures that when only radiation is considered, the temperatures of 461 both the storage layer and upper layer reach high (and obviously unphysical) values and that 462 means it has a small effect on the temperature of the UCZ and the LCZ. With evaporation 463 temperatures in the UCZ and LCZ become low; the lowest values for the temperature in both 464 layers (UCZ and LCZ) are observed with only evaporation case. For the UCZ, the 465 temperature in case of evaporation only is lower than temperature when three types of heat 466 loss are considered. To explain this behaviour it is helpful to plot the ambient temperature in 467 area of the pond (Kuwait) with the temperature of the UCZ. The profiles of both temperatures 468 are illustrated in figure 15. 


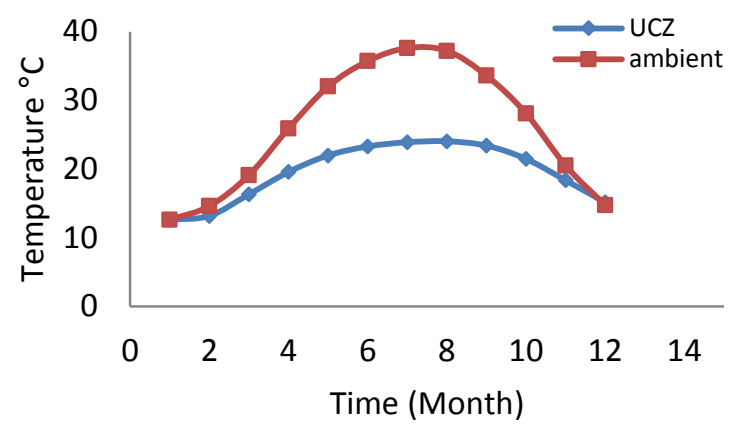

469

$470 \quad$ Figure 15 profiles of both the ambient and the calculated temperatures of UCZ.

471 It can be seen that the ambient temperature is higher than the temperature of the UCZ for 472 most months during the year. That means heat could be transferred from the atmosphere to 473 the pond according to the equation 11. In the El-Paso pond it is observed that ambient 474 temperature is higher than upper layer temperature of the pond for most months through one 475 year (Huanmin et al, 2001). The data which published by the researchers is plotted and 476 demonstrated in figure 16.

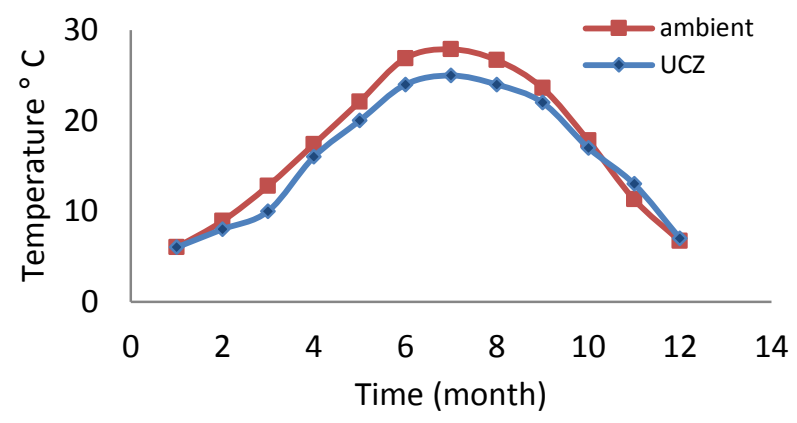

Figure 16 Profiles of both measured ambient and UCZ temperatures for El-Paso pond (1999), extracted from (Huanmin et al, 2001).

480 It is clear from figure 17 that ambient temperature is higher than temperature of the upper 481 layer. The difference continues from the first month to October when it becomes very small. Evaporation even occurs at temperatures lower than ambient temperature. With all cases there is an energy which is added from the surrounded air, but with evaporation only, there is no heat addition.

\section{Conclusion}

This paper has presented a model to calculate temperature in the three zones of a SGSP. The results are validated by comparison with experimental data and a good agreement has been obtained. It is noticed that temperature of a model pond in Kuwait reaches around $90{ }^{\circ} \mathrm{C}$ in 
July and decreases to around $50{ }^{\circ} \mathrm{C}$ at the end of the year. Obviously, a solar pond can supply heat temporarily during the year, even in winter with cloudy and cold weather, but it needs time to warm up. In the unburied ponds, temperature in the LCZ is higher than normal buried pond. It is concluded that perimeter has a significant effect on the LCZ temperature in the case of the small ponds, whereas the effect is unsubstantial in the case of the large ponds. Consequently, the shape of the small pond is important because perimeter changes with shape. The relative importance of evaporation, convection and radiation heat loss from the surface has been investigated. It is found that heat loss from surface by evaporation has the largest effect on the temperature of the LCZ whereas radiation has the smallest impact. Studies on evaporation and trying to decrease its impact will be useful and they might significantly increase efficiency of the salt gradient solar pond.

\section{References}

Alagao, F. B., Akbarzadeh, A., Johnson, P., 1994. The design, construction, and initial operation of closed- cycle salt gradient solar pond. Solar Energy 53, 343-351.

Alagao, F. B., 1996. Simulation of the transient behaviour of a closed-cycle salt- gradient solar pond. Solar Energy 56 (3), 245-260.

AbdelSalam, M., 1985. A multipurpose shallow solar pond (MSSP). Solar \& Wind Technology. 1, (3) 167-174.

Alenezi I., 2012. Salinity gradient solar ponds: Theoretical modelling and integration with desalination. PhD's Thesis, University of Surrey. Available at: http://epubs.surrey.ac.uk/745998/1.(Accessed:15 February 2014).

Ali, H.M., 1986. Mathematical modelling of salt gradient solar pond performance. Energy research (10) 377-384.

AL-Jamal, K., Khashan, S., 1998. Effect of energy extraction on solar pond performance. Energy convers.Mgmt. 39 (7) 559-566.

Alrowaished A., Azni I., Thamer A.Mohamed, Amimul A., 2013. The development and applications of solar pond: a review. Desalination and water treatment 1-13.

Anderson, A.L.,1980. Solar Pond What are they? Second industrial Energy Technology Conference .Houston, TX, 13-16 April.

Andrews, J., Akbarzadeh, A., 2005. Enhancing the thermal efficiency of solar ponds by extracting heat from the gradient layer. Solar Energy 78 (6), 704-716. 
524 Benjamin Schober, 2010. MEMBRANE STRATIFIED SOLAR PONDS. Master's Thesis, 525 University of Gavle. Available at:

526 http://www.diva-portal.org/smash/get/diva2:326646/FULLTEXT01 (Accessed:20 February 527 2014).

528 Bryant, H.C., Colbeck, I., 1977. A solar pond for London? Solar Energy 19 (3), 321-322.

529 Date, A., Yusli Y., Ashwin D., Shankar K., Akbarzadeh, A., 2013. Heat extraction from Non530 Convective and Lower Convective zones of the solar pond: A transient study. Solar Energy $53197,517-528$.

532 Date, A., Akbarzadeh, A., 2013. Salinity gradient solar ponds, in: Napoleon, E., Akbarzadeh, 533 A.,(Eds.,) Energy sciences and engineering applications. CRC press .E. Book.

534 Garman, M.A., Muntasser, M.A., 2008. Sizing and thermal study of salinity gradient solar 535 ponds connecting with MED desalination unit. Desalination (222), 689-695.

536 Garg, H.P., 1987. Advance in solar energy technology, collection and storage systems. 537 springer (1), Holland, direct publishing company.

538 Huanmin Lu, John, C., W., Andrew, H. P., 2001. Desalination coupled with salinity gradient 539 solar ponds. Desalination 136, 13-23.

540 Huanmin Lu, John C. W., Andrew H.P., Herbert, D. H., 2004. Advancements in salinity 541 gradient solar pond technology based on sixteen years of operational experience. Journal of 542 Solar Energy Engineering 126, 759 - 767.

543 Hull, J.R., 1980. Method and means of preventing heat convection in a solar pond. United 544 States Patent, No.4, 241, 724.Available at: http://www.google.com/patents/US4241724 545 (Accessed :20 April 2014).

546 Hull, J. R., K.V. Liu, W.T. Sha, Jyoti, K., Nielsen, C. E., 1984. Dependence of ground heat 547 loss upon solar pond size and perimeter insulation, calculated and experimental results. Solar 548 Energy33 (1), 25-33.

549 Hull, J. R., Nielsen, C. E., Golding, P., 1988. Salinity gradient solar ponds, CRC Press, 550 Florida. .

551 Jaefarzadeh, M. R., 2004. Thermal behaviour of a small salinity-gradient solar pond with wall 552 shading effect. Solar Energy 77, 281-290.

553 Jaferzadeh, M. R., 2005. Thermal behaviour of a large salinity-gradient solar pond in the city 554 of Mashhad. Iranian journal of science and Technology, Transaction Engineering, 29, No.B2. 
Karakilcik, M., Dincer, I., Marc, A. R., 2006. Performance investigation of a solar pond. Applied Thermal Engineering 26, 727-735.

Kishore, V.V.N., Veena, J., 1984. A practical collector efficiency equation for nonconvecting solar ponds. Solar Energy 33 (5), 391-395.

Kooi, C. F., 1979. The steady state salt gradient solar pond. Solar Energy 23, 37-45.

Leblanc J., Akbarzadeh, A., Andrews, J., Huanmin Lu, Golding, P., 2011. Heat extraction methods from salinity-gradient solar ponds and introduction of a novel system of heat extraction for improved efficiency. Solar Energy 85, 3103-3142.

Madani, S. S., 2014. Effect of different parameters on solar pond performance. Asia Pacific journal of energy and environment $1,(1)$.

McAdams, W.H., 1954. Heat transmission. 3rd edition, McGraw-Hill Kogakusha, Tokyo, Japan .

Nielsen, E. C., 1975. Salt-gradient solar ponds for solar Energy Utilization, Environmental conservation. The foundation of environmental conservation Vol. 2, No.4, printed in Switzerland.

Rabl, A., Nielsen, C. E., 1975. Solar ponds for space heating. Solar Energy 17, 1-12.

Safwan, K., Jonathan, D., Gregory, L., 2014. A simple heat and mass transfer model for salt gradient solar ponds. International journal of mechanical, industrial science and engineering 8 (1), 27-33.

Sodha, M. S., J. K. Nayak, Kaushik, S. C., 1980. Physics of shallow solar pond water heater. Energy Research 4,323-337.

Srinivasan, J., 1993. Solar pond technology. Sadhana, Vol.18, (1) (March), 39-55. Printed in India.

Surface Meteorology and solar energy, a renewable energy resource web site, available at https://eosweb.larc.nasa.gov (NASA) (accessed : 25 March 2014).

Velmurugan, V., Srithar, K., 2008. Prospects and scopes of solar pond: A detailed review. Renewable and Sustainable Energy Reviews 12, 2253-2263.

Wang, Y. F., Akbarzadeh, A., 1983. A parametric study on solar ponds. Solar Energy 30 (6), $555-562$.

Weinberg, J., Doron, B., 2010. Desalination and water resources, renewable energy system and desalination. ISBN: 978-1-84826-430-4. 
586 Wilkins, E., M. El-Genk, El-Husseini, K., Thakur, D., 1982. An evaluation of the gel pond 587 performance. THE AMERICAN SOCIETY OF MECHANICAL ENGINEERS, 345E. 47 St., 588 New York, N. Y. 10017.

589 Wilkins, E., T. K. Lee, 1987. Design and Optimization of the Gel Solar pond. The Canadian 590 Journal of Chemical Engineering (65), June.

591

592

593 